\section{Por un hilo}

\section{By a thread}

\section{ABSTRACT}

The incidence of benign obstructive central airway disease has been increasing. There are several causes for this type of obstruction. The most common appears after orotracheal intubation and post-tracheotomy. The diagnosis of tracheal stenosis requires clinical suspicion and complementary diagnostic tests.

The authors describe the case of a patient who showed respiratory distress and dyspnoea that had biphasic stridor, with no changes in cardiopulmonary auscultation or in blood samples. Chest $X$-ray revealed severe narrowing of the tracheal air column at C7 level, confirmed by CT scan.

This report shows a rare case of tracheal stenosis, with images of clinical interest and relevance, that can alert scientific community to this situation.

Palabras clave: estenosis traqueal, post-intubación, vía aérea central obstructiva Keywords: tracheal stenosis, post-intubation, obstructive central airway

\section{CASE REPORT}

There are several causes for benign obstructive central airway disease, including tracheomalacia, conditions that can cause chronic airway inflammation such as sarcoidosis, infectious or collagen diseases ${ }^{1}$. Nevertheless, the most common causes are secondary obstructions to orotracheal intubation and post-tracheostomy ${ }^{1,2}$.

Orotracheal intubation is associated with several types of complications ${ }^{1}$ which can be divided into immediate or late complications, such as traumatic upper airway injuries or post-intubation tracheal stenosis, respectively ${ }^{3}$.

The incidence of tracheal stenosis after intubation is from 6 to $21 \%$, according to some authors ${ }^{4,5}$. Several risk factors may contribute to its onset, such as prolonged or traumatic intubation, old age, female gender, or the presence of comorbidities such as diabetes mellitus $^{1,5,6}$. Patients may exhibit cough, dyspnoea or stridor ${ }^{1,5}$, and these manifestations depend on location, degree and speed of tracheal lumen narrowing ${ }^{1}$.

The diagnosis of tracheal stenosis requires clinical suspicion and complementary diagnostic tests such as respiratory function tests ${ }^{1}$, chest X-ray and computed tomography scan ${ }^{1,3}$. Bronchofibroscopy is important for a treatment approach, ${ }^{7}$ which may be endoscopic or surgical ${ }^{1,2,5,8}$.

The authors describe the case of a 46-year-old male patient who exhibited respiratory distress and dyspnoea on minor exertion for approximately two weeks and was hospitalized for etiological study. This patient had a possible alcoholic liver disease (MELD 18 points, Child-Pugh C12) and was hospitalized due to rupture of oesophageal varicose veins requiring invasive mechanical ventilation for 5 days for airway protection, two weeks prior to the onset of this condition. The patient had biphasic stridor, with no changes in cardiopulmonary auscultation or in blood samples. Chest $X$-ray revealed narrowing of the tracheal air column at C7 level. A cervical computed tomography scan showed an area of intense narrowing of the tracheal lumen in the lower cervical region, with relatively regular limits (Figure 1), and no other changes. Flexible bronchofibroscopy showed eccentric stenosis with $5 \mathrm{~mm}$ in diameter at the level of the isthmus of the thyroid gland.

The patient underwent airway reconstruction surgery with excision of three tracheal rings and end-to-end anastomosis, with good outcome and symptom resolution.

Post-intubation tracheal stenosis is the most frequent cause of reconstructive tracheal surgery ${ }^{4,6,9}$ and remains a surgical challenge ${ }^{10}$.
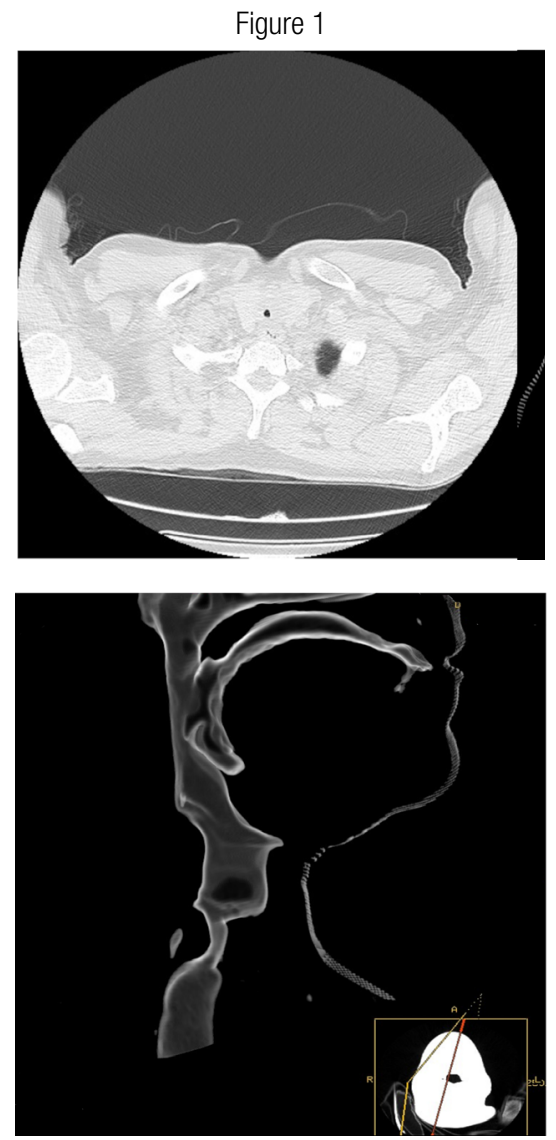

This article illustrates a case of post-intubation stenosis which, despite being a rare complication, can be life-threatening, so the authors highlight the importance of considering this diagnosis when there are suggestive symptoms to perform early,4,9 appropriate and effective treatment.

Acknowledgements: Dr Nuno Neves, for selecting and reconstructing the images of the clinical case.

\section{REFERENCES}

1. Barros Casas D, Fernández-Bussy S, Folch E, Flandes Aldeyturriaga J, Majid A. Nonmalignant central airway obstruction. Arch Bronconeumol. 2014;50(8):345-354.

2. Shin B, Kim K, Jeong BH, et al. Clinical significance of differentiating post-intubation and post-tracheostomy tracheal stenosis. Respirology. 2017;22(3):513-520.

3. Donatelli J, Gupta A, Santhosh R, et al. To breathe or not to breathe: a review of artificial airway placement and related complications. Emerg Radiol. 2015;22(2):171-179.

4. Farzanegan R, Feizabadi M, Ghorbani F, et al. An Overview of Tracheal Stenosis Research Trends and Hot Topics. Arch Iran Med.

5. Jung YR, Taek Jeong J, Kyu Lee M, et al. Recurred Post-intubation Tracheal Stenosis Treated with Bronchoscopic Cryotherapy. Intern Med. 2016;55(22):3331-3335.

6. Songu M, Ozkul Y. Risk Factors for Adult Postintubation Tracheal Stenosis. J Craniofac Surg. 2019;30(5):e447-e450

7. Nakamura M, Hisamura M, Hashimoto $\mathrm{M}$, et al. Membranous tracheal stenosis in a patient with anorexia nervosa and self-induced vomiting- challenges in securing the airway. Respir Med Case Rep. 2017;21:36-38

8. Viveiros F, Gomes J, Oliveira A, Neves S, Almeida J, Moura e Sá J. Topical application of mitomycin-C as an adjuvant treatment to bronchoscopic procedures in post-intubation tracheal stenosis. Rev Port Pneumol. 2013;19(6):276-280.

9. Farzanegan R, Farzanegan B, Alehashem M, et al. Item Selection and Content Validity of the Risk Factors of Post-Intubation Tracheal Stenosis Observation Questionnaire for ICLAdmitted Patients. Tanaffos. 2017;16(1):22-33.

10. Wright CD, Li S, Geller AD, et al. Postintubation Tracheal Stenosis: Management and Results 1993 to 2017. Ann Thorac Surg. 2019;108(5):1471-1477.

\section{Catarina Cascais Costa ${ }^{1}$, Cláudia Rosado²}

${ }^{1}$ Departamento de Pneumologia, ${ }^{2}$ Departamento de Medicina Interna, Centro Hospitalar Baixo Vouga .

Correspondencia: catarinacascaisc@gmail.com

Cómo citar este artículo: Cascais Costa $\mathrm{C}$, Rosado $\mathrm{C}$

Por um fio. Galicia Clin 2021; 82-3: 175

Recibido: 24/3/2020; Aceptado: 2/2/2021 // https://doi.org/10.22546/62/2279 